\title{
Seasonal variation in breeding Rüppell's Vultures Gyps rueppellii at Kwenia, southern Kenya and implications for conservation
}

\author{
MUNIR Z. VIRANI, ARA MONADJEM, SIMON THOMSETT and \\ CORINNE KENDALL
}

\begin{abstract}
Summary
Vulture populations have been declining globally and regionally within Africa. Rüppell's Vulture Gyps rueppellii is currently listed as 'Near Threatened' and numbers of the species, along with African White-backed Vultures G. africanus, have declined by $52 \%$ in and around the MaraSerengeti ecosystem. A large breeding colony of Rüppell's Vulture at Kwenia, southern Kenya, was monitored between 2002 and 2009. Around 150-200 adults were present on each visit, with up to 64 simultaneously active nests. The date of egg-laying differed considerably between years, with two discrete breeding attempts in some years. Nests were not positioned randomly across the cliff face and the number of active nests was related to rainfall in the previous year. The large ungulate migration of the Mara-Serengeti provides a vital foraging ground for the species. Conservation implications of the loss of vultures are discussed.
\end{abstract}

\section{Introduction}

There is currently global concern about vulture population declines across the Old World. Catastrophic declines of populations of Gyps vultures have been recorded in south Asia (Gilbert et al. 2002, Prakash et al. 2003). Three species of Gyps vultures breed in sub-Saharan Africa, and all have declining populations; regional declines have been reported for West Africa (Thiollay 2006a,b), southern Africa (Bamford et al. 2007, Boshoff et al. 2009) and Kenya (Ogada and Keesing 2010, Virani et al. 2011). The Cape Vulture G. coprotheres is listed as 'Vulnerable', while the African White-backed G. africanus and Rüppell's Vultures are listed as 'Near Threatened' (BirdLife International 2011).

As a result of local concern (Virani and Muchai 2004), ongoing research on vultures in East Africa is highlighting new information about their population sizes, behaviour, mortality and movement patterns, critical in ensuring that conservation strategies are based on sound science (Ogada and Keesing 2010, Ogada and Buij 2011, Virani et al. 2011, Kendall et al. Unpubl. data). Current studies suggest declines in both the range and numbers of various vulture species as a result of compound threats including poisoning (Otieno et al. 2010) and changes in land-use practices (Ogada and Keesing 2010, Virani et al. 2011, Ogada and Buij 2011). Rüppell's Vulture was formerly widely distributed throughout Kenya, although breeding has always been restricted to a relatively small number of cliffs scattered in the south and north of the country (Lewis and Pomeroy 1989). Although its breeding biology has not been reported for Kenya, Houston (1990) documented two breeding seasons of a subset of a large colony exceeding 1,00o nests in the Gol Mountains of northern Tanzania. In each year, breeding was synchronised within the colony, but the timing of egg-laying varied considerably between the two years (Houston 1990). 
Knowledge of the nesting activity of the species would assist development of a long-term conservation plan for Kwenia, which currently does not enjoy any legal protection. The aim of this paper is to report on the influence of seasonal variation, particularly rainfall, on the number of Rüppell's Vultures roosting and nesting at Kwenia, which represents the largest breeding colony of this species in southern Kenya.

\section{Methods}

\section{Study site}

Kwenia $\left(1^{\circ} 46^{\prime} 38.21^{\prime \prime} \mathrm{S}\right.$ and $\left.36^{\circ} 31^{\prime} 5.24^{\prime \prime} \mathrm{E}\right)$ is situated in Kajiado district, southern Kenya approximately $80 \mathrm{~km}$ south of Nairobi (Figure 1). Most of Kajiado District is semi-arid with poorly developed and shallow soils (vertisols) with high clay content. Rainfall is bimodal with annual average of $600 \mathrm{~mm}$, increasing with elevation from $500 \mathrm{~mm}$ in the plains to $1,250 \mathrm{~mm}$ in the highlands. Temperatures also vary with altitude and range from $12{ }^{\circ} \mathrm{C}$ in the highlands to $34^{\circ} \mathrm{C}$ in plains (Gichuki et al. 1998). The predominant land use in the area is pastoral herding of goats and cattle.

The cliffs at Kwenia are west-facing and approximately $2 \mathrm{~km}$ in length and on average about $140 \mathrm{~m}$ high. Despite the large size of the colony at Kwenia, this site was not surveyed prior to this

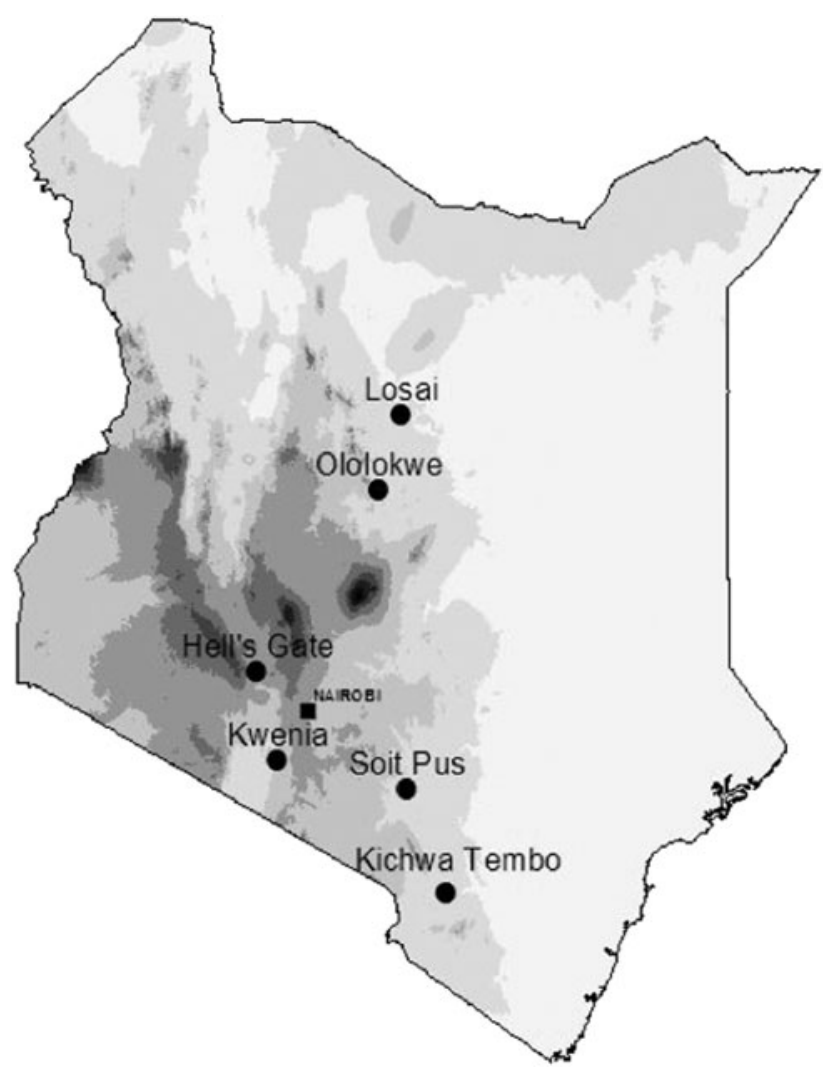

Figure 1. Map of Kenya and the position of Kwenia on a digital elevation model (showing altitude). Also shown are the known nesting sites (black circles) of Rüppell's Vultures in Kenya. 
study, although it is mentioned by Pennycuick (1983) as having a "large colony" with possibly several hundred nest sites.

\section{Data collection}

Kwenia was visited at irregular intervals from October 2002 to May 2009. An attempt was made to visit Kwenia at least twice per year, but during 2002, 2003, 2007 and 2008 it was visited just once.

Our vulture surveys had two objectives: 1 ) to count all adult and immature Rüppell's Vultures present on the cliffs, and 2) to record all active and occupied nests on the cliffs at Kwenia. Vulture counts commenced at first light (around o6h3o) and were completed within two hours (before adult birds had left the cliffs). At least two observers were present during each count. Cliffs were scanned with a telescope starting from one end and gradually proceeding to the other. The cliff face was divided into eight unequal sections based on prominent landmarks (such as cracks or crevices) plus the amount of whitewash present. Nests were identified by the accumulation of nesting material or if a vulture was observed incubating. Each of the eight sections of the cliff face was photographed using a digital camera, and potential nesting ledges and confirmed nest sites were marked with a unique alpha-numeric code on a printed copy of the image. Confirmation of an occupied and/or active nest was based on the following: 1) bird (or birds) standing on nest and no chick seen, 2) bird sitting on nest and no chick seen, and 3) confirmed breeding - chick seen. The first two behaviours indicated an occupied nest, while the third an active nest (Postupalsky 1973). Thus an active nest will be occupied while an occupied nest may not necessarily be active. In addition to recording the presence of chicks on the nest, juvenile (recently fledged) birds on the cliffs were also recorded.

Rainfall data were obtained from the Magadi Soda Company located about $20 \mathrm{~km}$ from Kwenia (http://www.magadisoda.co.ke).

\section{Data analysis}

Spearman's rank correlation was conducted to test for associations between variables. Values are presented as means $\pm \mathrm{SD}$.

\section{Results}

The number of adult Rüppell's Vultures counted on the cliff face at Kwenia between 2003 and 2009 ranged from a high of 254 birds in March 2005 to a low of 81 birds in September 2005 (Figure 2). Between March 2005 and September 2005 there was a considerable decline in the number of adult vultures at Kwenia, with numbers slowly increasing between May 2006 and March 2008. Between October 2002 and October 2004, and again between March 2008 and May 2009, numbers of adults were stable at between 150 and 200 birds (Figure 2). The mean number of birds per year between 2002 and 2009 was $168.9 \pm 18.2$ ) while the mean number of active/ occupied nests per annum during this period was $47.6 \pm 11.6$ ).

The maximum number of nests that were active per annum varied only slightly between years (Figure 3) and was not correlated with either the number of adults present that year or the previous year ( $r=-0.054$ and -0.324 , respectively, $P>0.05$ for both analyses). However, there was a significant inverse relationship between the number of active nests and rainfall in the previous year $(r=-0.818, P=0.025, n=6)$.

The timing of nesting varied from year to year (Figure 4). In October 2002, when the study was initiated, there were no actively nesting adult birds at Kwenia. A year later in October 2003, a small proportion (less than a quarter) of the adults present were incubating (Figure 4). By January 2004, the proportion of incubating adults had increased and chicks were also visible in nests. Five months later in June 2004 there were no incubating adults, but there was a chick in each 


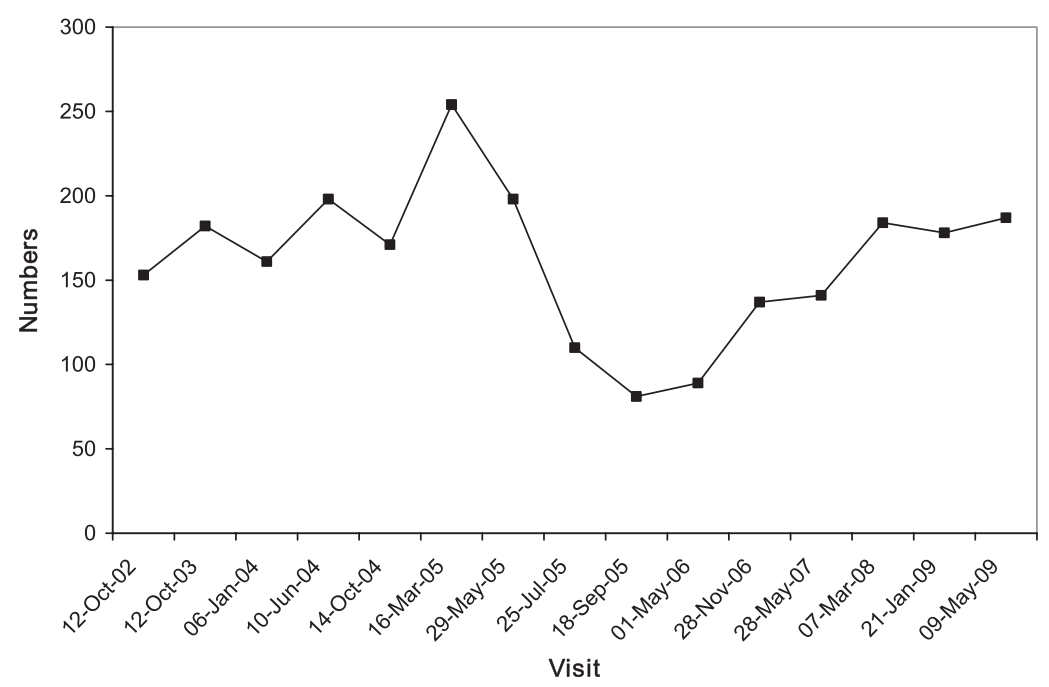

Figure 2. Number of adult Rüppell's Vultures present at each visit on the cliff face at Kwenia between October 2002 and May 2009.

active nest (Figure 4). This suggests that in 2003 and 2004 the vultures had laid eggs in September and/or October. In 2005, however, the majority of adults were incubating in late July, with a small number of chicks present suggesting that eggs were laid in June of that year. Similarly, all the adult birds were incubating in May 2006 (Figure 4) suggesting that eggs were laid in April or May. A small number of adult birds were incubating again in November (Figure 4), indicating that the vultures had two breeding seasons in 2006. The vultures also bred twice in 2009. Hence, laying dates varied significantly between years (Table 1 ).

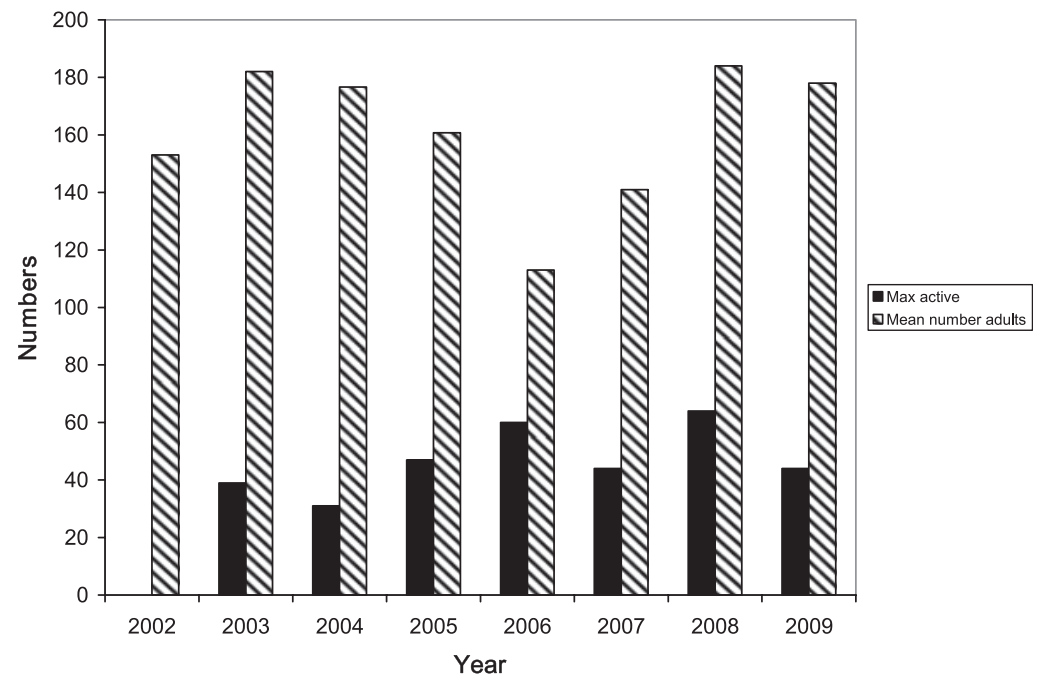

Figure 3. Mean number of adult Rüppell's Vultures present on the cliff face at Kwenia, together with the maximum number of active nests present in each year. 


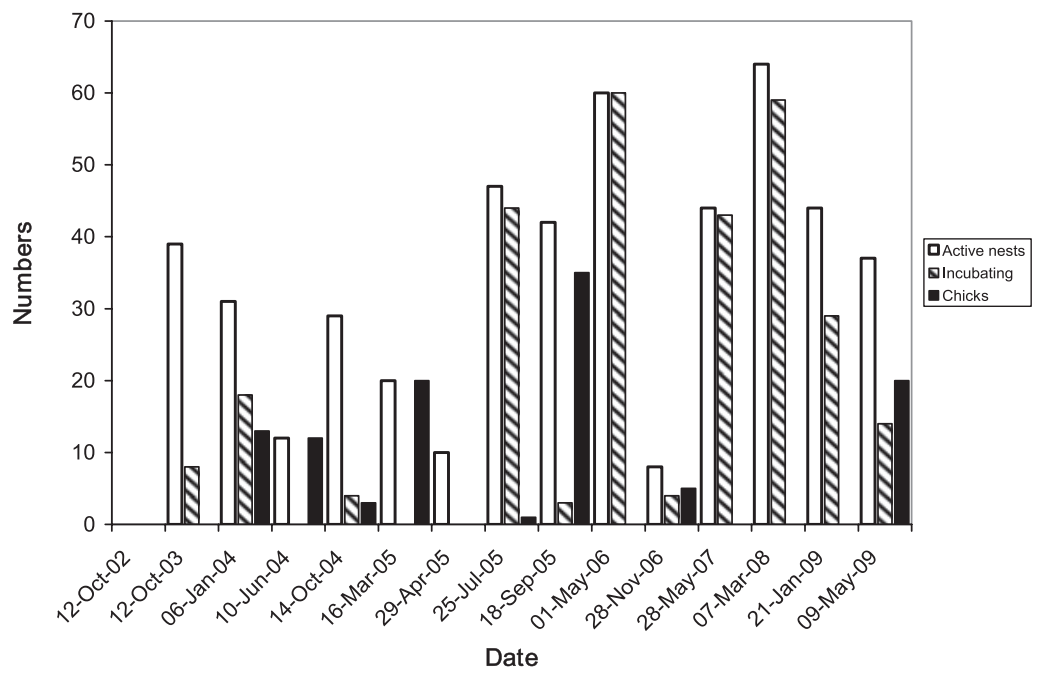

Figure 4. Numbers of active nests, incubating adults, and chicks of Rüppell's Vultures at Kwenia between October 2002 and May 2009.

There was significant variation in the location of occupied/active nests at the Kwenia cliff face (Table 1 ). Sections 3, 5, 8 and 9 supported most of the occupied/active nests, while section 1 only had a single active nest in the seven-year study period.

Table 1. Estimated date of egg-laying in Rüppell's Vultures at Kwenia between 2002 and 2009, based on data presented in Figure 4 and number of active nests at each of the eight sections of the Kwenia cliff face, on each of the 15 visits between October 2002 and May 2009. Also shown are the total and mean number of active nests and standard deviation (SD) for each site.

\begin{tabular}{|c|c|c|c|c|c|c|c|c|c|c|c|}
\hline \multirow[t]{2}{*}{ Year } & \multirow{2}{*}{$\begin{array}{l}\text { Estimated } \\
\text { date of egg } \\
\text { laying }\end{array}$} & & \multicolumn{8}{|c|}{ Sections } & \multirow[b]{2}{*}{ Total } \\
\hline & & & 1 & 2 & 3 & 5 & 6 & 7 & 8 & 9 & \\
\hline 2002 & Unknown & 12-Oct-O2 & o & o & o & o & o & o & o & o & o \\
\hline 2003 & Sept/Oct & $12-O c t-03$ & 1 & o & 9 & 9 & 1 & 8 & 10 & o & 38 \\
\hline \multirow[t]{3}{*}{2004} & Oct & o6-Jan-04 & o & 1 & 10 & 11 & 1 & $\mathrm{O}$ & 3 & 5 & 31 \\
\hline & & 10-Jun-O4 & o & 1 & 2 & 4 & 1 & 1 & 3 & o & 12 \\
\hline & & 14-Oct-O4 & o & 1 & 2 & o & 14 & 1 & 3 & 8 & 29 \\
\hline \multirow[t]{4}{*}{2005} & Jun & 16-Mar-05 & o & o & o & o & 9 & o & 8 & 3 & 20 \\
\hline & & 29-Apr-05 & o & o & 7 & o & 3 & o & o & o & 10 \\
\hline & & 25 -Jul-05 & o & 3 & 10 & 11 & 6 & 2 & 10 & 5 & 47 \\
\hline & & 18-Sep-o5 & o & 2 & 7 & 7 & 3 & $I$ & 10 & 12 & 42 \\
\hline 2006 & Apr/May & о1-Мay-o6 & o & 5 & 11 & 13 & 4 & 5 & 10 & 12 & 60 \\
\hline 2006 & $\mathrm{Oct} / \mathrm{Nov}$ & 28-Nov-06 & o & o & o & $\mathrm{o}$ & o & 1 & 3 & 4 & 8 \\
\hline 2007 & Apr/May & 28-May-o7 & o & 2 & 6 & 8 & 3 & 2 & 13 & 10 & 44 \\
\hline 2008 & Feb/Mar & 07-Mar-o8 & o & o & 11 & 11 & 6 & 6 & 14 & 16 & 64 \\
\hline 2009 & Jan & 21-Jan-09 & $\mathrm{o}$ & o & 10 & 10 & 4 & 3 & 9 & 8 & 44 \\
\hline \multirow[t]{4}{*}{2009} & May & o9-May-o9 & o & o & 9 & 10 & 2 & 2 & 8 & 6 & 37 \\
\hline & & Total & 1 & 15 & 94 & 94 & 57 & 32 & 104 & 89 & 486 \\
\hline & & Mean & 0.07 & 1.00 & 6.27 & 6.27 & 3.80 & 2.13 & 6.93 & $5 \cdot 93$ & \\
\hline & & SD & 0.2582 & 1.4639 & 4.2840 & 5.0209 & 3.7645 & 2.4162 & 4.5429 & 5.0351 & \\
\hline
\end{tabular}




\section{Discussion}

Based on the number of adults and occupied/active nests observed, Kwenia is probably the most important breeding location for Rüppell's Vulture in southern Kenya (Lewis and Pomeroy 1989). The only other site in Kenya that has been surveyed for this species is Hell's Gate National Park (about $150 \mathrm{~km}$ east of Kwenia), where approximately 15-20 pairs breed per annum (Iwhagi, M. Virani unpubl. data). Hence, the Kwenia colony is at least an order of magnitude larger than that at Hell's Gate. The cliffs at Mount Ololokwe in northern Kenya are known to support large numbers of Rüppell's Vultures (S. Thomsett pers. obs.); however, the birds and nests at this site have not been studied systematically. The most important breeding site in East Africa appears to be the Gol mountains in northern Tanzania, but no surveys have been conducted there since those undertaken in 1969-1970 Houston (1976) and 1973 (Pennycuick 1983). Houston (1976) estimated that the colony comprised about 1 ,ooo pairs, but did not provide any details of how this figure was derived. Pennycuick (1983) estimated a total of 1,500-3,000 pairs in Tanzania based on aerial surveys using a light aircraft. Although the total number of pairs breeding in Kenya is still unknown, it is probably an order of magnitude smaller than the Tanzanian figure.

It is not known what caused the drop in numbers of adult birds from July 2005 to May 2006. One plausible explanation that cannot be discounted at this stage is direct mortality through poisoning as has been documented on other vulture species (Margalida et al. 2008, Hernández and Margalida 2009). Major poisoning incidents by use of carbamate pesticides were reported for the first time in 2004 where 187 vultures of three species (African White-backed, Rüppell's and Lappet-faced Aegypius tracheliotos) were poisoned near the Athi-Kitengela plains (Otieno et al. 2010) just $60 \mathrm{~km}$ north-west of Kwenia. Based on movement studies, this area appears to be frequented by Rüppell's Vultures nesting in Kwenia (C. Kendall and M. Virani unpubl. data). An alternative explanation is that Kwenia acts as a major roosting site for non-breeding adults that may have temporarily moved away to a different location (perhaps due to scarcity of food in that region of Kenya). In this regard, wing-tagging and tracking adult Rüppell's Vultures may be important for understanding their movements in response to changing conditions as well as to obtain more accurate mortality rates.

Considering the size of the Kwenia colony, we suggest that Kwenia may act as an important focal point for Rüppell's Vultures in southern Kenya and northern Tanzania. In Namibia, satellite-tagging of the closely related Cape Vultures (Johnson et al. 2006) showed that they ranged over large areas, with adults covering a mean of $21,320 \mathrm{~km}^{2}$ and juveniles $482,276 \mathrm{~km}^{2}$ (Bamford et al. 2007). Past radio-tracking of two Rüppell's Vultures in Tanzania indicated that they moved between the Gol cliffs and the Serengeti plains; a distance in excess of $100 \mathrm{~km}$ (Pennycuick 1983). In 2009, a GSM-GPS (cell phone) tracking device attached to an adult Rüppell's Vulture trapped in the Masai Mara showed it frequently roosting at Kwenia. Its movements showed that vultures roosting or nesting at Kwenia range widely using Masai Mara National Reserve in Kenya and Serengeti National Park, Maswa Game Reserve, and Ngorongoro Conservation Area, Tanzania (C. Kendall and M. Virani, unpubl. data). This same individual travelled an average of $65 \mathrm{~km}$ per day with a total range size of $71,990 \mathrm{~km}^{2}$ over a 10-month period. Gyps vultures are capable of moving long distances between roosting/nesting sites and foraging grounds (Pennycuick 1983, Bamford et al. 2007) and thus Rüppell's Vultures using Kwenia likely range across much of East Africa and probably beyond its northern borders in the Sudan and Ethiopia where suitable cliffs occur.

Similar numbers of nests were occupied/active in different years of the study, suggesting that the breeding population was stable. The maximum number of occupied/active nests in a year was not related to the number of adult birds in the population, pointing to a variable number of nonbreeding adults. The inverse relationship between the number of occupied/active nests and rainfall in the previous year may be related to greater food availability for scavengers in dry or drought years, stimulating breeding in the following season (Mduma et al. 1999, Ogutu et al. 2008). A similar inverse relationship between rainfall and nesting activity was reported for Lappet-faced 
Vultures breeding in Namibia (Bridgeford and Bridgeford 2003). In addition, like other large birds, vultures rely on thermals for soaring flight and thus their ability to search for carrion may also be limited by rainfall (Pennycuick 1972, Monadjem and Bamford 2009). Although the impacts of climate change on rainfall in East Africa are debated (Williams and Funk 2010), if rainfall increases as originally predicted by Christiansen et al. (2007), food availability and soaring ability of vultures would be likely to decrease, leading to declines in breeding activity and population dynamics as has been documented for European vultures (Margalida et al. 2010, 2011).

In this study, the date of egg laying by Rüppell's Vultures at Kwenia varied from year to year, an observation also made by Houston (1976). In contrast, the Cape Vulture Gyps coprotheres in southern Africa has a clearly defined breeding season with egg-laying commencing in April/May (Mundy et al. 1992). The African White-backed Vulture also does not vary its egg-laying date between years in southern Africa (Mundy et al. 1992). In East Africa however, the breeding of this species is bimodal with nesting in April/May and December/January (Ferguson-Lees and Christie 2001), with a peak in laying between March and May (Houston 1976). Nesting in Rüppell's Vulture may be triggered by rainfall and geared to producing fledged young at the end of the dry season (July-October) when carrion is most abundant (Houston 1976).

Different sections of the Kwenia cliff supported considerably different numbers of occupied/ active nests. Clearly Rüppell's Vultures do not treat the cliff face as being a uniform feature, preferring some parts of the cliff over others. Colonial seabirds often exhibit significant differences in breeding success between peripheral nests (on the edges of the colony) and central nests (in the middle of the colony) (Forster and Phillips 2009). Some nests on Kwenia, particularly the central cliffs, had guano deposits that were at least 2 metres in height which have probably been around for centuries (Houston and Nager 2009). This suggests that specific sites have been strongly chosen over millennia and implies that there is strong selection pressure for only a very few places. Future studies at Kwenia should focus on measuring a limited number of variables that might influence this choice, such as ledge size, shape, shelter, aspect and cliff features (Newton 1979).

Despite the many threats - poisoning, reduced food availability, disturbance, and climate change - and the recent evidence that populations of Gyps and other vultures in the nearby Masai Mara ecosystem have declined by $52 \%$ in the last thirty years, which is likely to be the same population as the Rüppell's Vultures using Kwenia, based on findings from telemetry (C. Kendall and M. Virani unpubl. data), nesting activity at Kwenia has remained remarkably stable. In addition, comparisons of current and historic carcass counts provide evidence that the proportion of Rüppell's Vultures has increased relative to African White-backed Vultures, suggesting that currently Rüppell's Vultures are not declining as rapidly as other scavengers (Kendall et al. In review). Reasons for these possible differences in the level of decline among avian scavengers are currently being explored. However, continued monitoring of Rüppell's Vultures at key nesting and foraging sites, such as Kwenia and Masai Mara, is critical given the existing threats.

The Rüppell's Vulture colony at Kwenia is the most important for the species in southern Kenya. Results of our study may be beneficial for any initiative attempting to provide Kwenia with some form of legal protection to safeguard this vital breeding stronghold. We recommend that Kwenia be considered for development into a wildlife conservancy with a community-based ecotourism venture that would bring economic benefits to the local community similar to other community projects in the region (Honey 2009).

\section{Acknowledgements}

This study is part of The Peregrine Fund's Pan African Raptor Conservation Program and was funded by grants from The Peregrine Fund. We are indebted to the Masai community living in the Kwenia, Kilonito, and Elanguata Was area of Kajiado and Magadi districts. In particular we would like to single out Titus and Magdalene Kaai for their tremendous help during the research. 
We are grateful to Mr Kores of the Kajiado County Council for his support and encouragement. Steven Okiri of the Magadi Soda Company assisted with rainfall data. We also thank the numerous volunteers who helped with data collection, sometimes under adverse conditions.

\section{References}

Bamford, A. J., Diekmann, M., Monadjem, A. and Mendelsohn, J. (2007) Ranging behaviour of Cape Vultures Gyps coprotheres from an endangered population in Namibia. Bird Conserv. Internatn. 17: 331-339.

BirdLife International (2011) Gyps africanus, Gyps coprotheres and Gyps rueppellii. IUCN Red List of threatened species. Version 2011.1. www.iucnredlist.org (downloaded 26 August 2011)

Boshoff, A. F., Piper, S. E. and Michael, M. (2009) On the distribution and breeding status of the Cape Griffon Gyps coprotheres in the Eastern Cape province, South Africa. Ostrich 80: 85-92.

Bridgeford, P. and Bridgeford, M. (2003) Ten years of monitoring breeding Lappetfaced Vultures Torgos tracheliotos in the Namib-Naukluft Park, Namibia. Vulture News 48: 3.

Christiansen, J. H., Hewitson, A., Busuioc, A. et al. (2007) Regional climate projections. Pp 849-940 in S. Solomon, D. Qin and M. Manning et al., eds. Climate change 2007: The physical science basis. Contribution of working group I to the fourth assessment report of the Intergovernmental Panel on Climate Change. Cambridge, UK: Cambridge University Press.

Ferguson-Lees, J. and Christie, D. A. (2001) Raptors of the world. London: Christopher Helm.

Forster, I. P. and Phillips, R. A. (2009) Influence of nest location, density and topography on breeding success in the black-browed albatross Thalassarche melanophris. Mar. Ornith. 37: 213-217.

Gilbert, M., Virani, M. Z., Watson, R. T., Oaks, J. L., Benson, P. C., Khan, A. A., Ahmed, S., Chaudhry, J., Arshad, M., Mahmood, S. and Shah, Q. A. (2002) Breeding and mortality of Oriental Whitebacked Vulture Gyps bengalensis in Punjab province, Pakistan. Bird Conserv. Internatn. 12: 311-326.
Gichuki, N. N., Oyieke, H. A., Ndiritu, G. G. and Handa, C. (1998) Wetland biodiversity in Kajiado District. Nairobi: National $\mathrm{Mu}-$ seums of Kenya, Centre for Biodiversity. (Technical Report no 3).

Hernández, M., and Margalida, A. (2009) Poison-related mortality effects in the endangered Egyptian vulture (Neophron percnopterus) population in Spain. Eur. J. Wildl. Res. 55: 415-423.

Honey, M. (2009) Community conservation and early ecotourism. Experiments in Kenya. Environment 51: 85-91.

Houston, D. C. (1976) Breeding of the Whitebacked and Rüppell's Griffon Vultures, Gyps africanus and Gyps rueppellii. Ibis 118: 14-40.

Houston, D. C. (1990) A change in the breeding season of Rüppell's Griffon Vultures Gyps rueppellii in the Serengeti in response to changes in ungulate populations. Ibis 132: 36-41.

Houston, D. C. and Nager, R. (2009) Archaeology among the bird droppings: what does it tell us about raptor nest site selection? Ibis 151: 592-593.

Johnson, J. A., Lerner, H. R. L., Rasmussen, P. C. and Mindell, D. P. (2006) Systematics within Gyps vultures: a clade at risk. BMC Evolutionary Biology 6: 65 doi:10.1186/ 1471-2148-6-65.

Lewis, A. and Pomeroy, D. E. (1989) A bird atlas of Kenya. Rotterdam, The Netherlands: Balkema.

Margalida, A., Colomer, M. A. and Sanuy, D. (2011) Can wild ungulate carcasses provide enough biomass to maintain avian scavenger populations? An empirical assessment using a bio-inspired computational model. PLOS ONE 6: e2O248.

Margalida, A., Donazar, J. A., Bustamante, J., Hernández, F. J. and Romero-Pujante, M. (2008) Application of a predictive model to detect long-term changes in nest-site selection in the Bearded Vulture Gypaetus 
barbatus: conservation in relation to territory shrinkage. Ibis 150: 242-249.

Margalida, A., Donázar, J. A., Carrete, M. and Sánchez-Zapata, J. A. (2010) Sanitary versus environmental policies: fitting together two pieces of the puzzle of European vulture conservation. J. Appl. Ecol. 47: 931-935.

Mduma, S. A. R., Sinclair, A. R. E. and Hilborn, R. (1999) Food regulates the Serengeti wildebeest: a 40-year record. J. Anim. Ecol. 68: 1101-1122.

Monadjem, A. and Bamford, A. J. (2009) Influence of rainfall on timing and success of reproduction in Marabou Storks Leptoptilos crumeniferus. Ibis 151: 344-351.

Mundy, P., Butchart, D., Ledger, J. and Piper, S. (1992) The vultures of Africa. London, UK: Academic Press.

Newton, I. 1979. The population ecology of raptors. Berkhamstead, UK: Poyser.

Ogada, D. L. and Keesing, F. (2010) Rapid decline of vultures over a three-year period in Laikipia, Central Kenya. J. Raptor Res. 44: 129-135.

Ogada, D. L. and Buij, R. (201) Large declines of the Hooded Vulture Necrosyrtes monachus across its African range. Ostrich 82: 101-113.

Ogutu, J. O., Piepho, H. P., Dublin, H. T., Bhola, N. and Reid, R. S. (2008) Rainfall influences on ungulate population abundance in the Mara-Serengeti ecosystem. J. Anim. Ecol. 77: 814-829

Otieno, P. O., Lalah, J. O., Virani, M., Jondiko, I. O. and Schramm, K-W. (2010). Carbofuran and its toxic metabolites provide forensic evidence for furadan exposure in vultures (Gyps africanus) in Kenya. Bull. Environ. Contam. Toxicol. 84: 536544.

Pennycuick, C. J. (1972) Soaring behavior and performance of some East African birds, observed from a motor-glider Ibis II4: 178-218

Pennycuick, A. J. (1983) Effective nest density of Rüppell's Griffon Vulture in the SerengetiRift Valley area of northern Tanzania. Pp. $172-184$ in S. R. Wilbur and J. A. Jackson, eds. Vulture biology and management. Berkeley, CA: University of California Press.
Postupalsky, S. (1974) Raptor reproductive success: some problems with methods, criteria, and terminology. $\mathrm{Pp} 21-31$ in F. N. Hamerstrom, B. E. Harrell and R. R. Olendorff, eds. Management of raptors. Proceedings of the conference on raptor conservation techniques, Fort Collins, Colorado. 22-24 March 1973. Vermillion, South Dakota: Raptor Research Foundation.

Prakash, V., Pain, D. J., Cunningham, A. A., Donald, P. F., Prakash, N., Verma, A., Gargi, R., Sivakumar, S. and Rahmani, A. R. (2003) Catastrophic declines of Indian white-backed Gyps bengalensis and longbilled G. indicus vulture populations. Biol. Conserv. 109: 381-390.

Thiollay, J-M. (2006a) The decline of raptors in west Africa: long-term assessment and the role of protected areas. Ibis 148: 240254.

Thiollay, J-M. (2006b) Large bird declines with increasing human pressure in savanna woodlands (Burkina Faso). Biodiv. Conserv.15: 2085-2108.

Virani, M. Z. and Muchai, M. (2004) Mara Vulture Workshop Resolution. Pp. 18-19 in M. Z. Virani and M. Muchai, eds. Vulture conservation in the Masai Mara National Reserve, Kenya. Proceedings and recommendations of a seminar and workshop held at the Masai Mara National Reserve, 23 June 2004. Nairobi: National Museums of Kenya. (Ornithology Research Report 57).

Virani, M. Z., Kirui, P., Monadjem, A., Thomsett, S., Githiru, M. (2010) Nesting densities of African White-backed Vultures Gyps africanus in the Masai Mara National Reserve, Kenya: some initial estimates. Ostrich 81: 205-209

Virani, M. Z., Kendall, C., Njoroge, P. and Thomsett, S. (2011) Major declines in the abundance of vultures and other scavenging raptors in and around the Masai Mara ecosystem, Kenya. Biol. Conserv. 144: 746-752.

Williams, A. P. and Funk, C. (2010) A westward extension of the warm pool leads to a westward extension of the Walker circulation, drying eastern Africa. Clim. Dyn. DOI 10.1007/s00382-010-0984-y 
MUNIR Z. VIRANI*

The Peregrine Fund, 5668 West Flying Hawk Lane, Boise Idaho 83709 USA, and Ornithology Section, Department of Zoology, National Museums of Kenya, P.O Box 40658-0o1oo Nairobi, Kenya.

ARA MONADJEM

All Out Africa Research Unit, Department of Biological Sciences, University of Swaziland, Private Bag 4, Kwaluseni, Swaziland.

\section{SIMON THOMSETT}

Ornithology Section, Department of Zoology, National Museums of Kenya, P.O Box 40658-0010o Nairobi, Kenya.

\section{CORINNE KENDALL}

Department of Ecology and Evolutionary Biology, Princeton University NJ, USA, and Ornithology Section, Department of Zoology, National Museums of Kenya, P.O Box 40658-0010o Nairobi, Kenya.

*Author for correspondence; email tpf@africaonline.co.ke

Received 10 August 2010; revision accepted I August 2011; Published online 28 March 2012 